\title{
EFFECT OF FORMING TOOLS NOSE ON THE FORMABILITY OF SINGLE POINT INCREMENTAL SHEET FORMING
}

\author{
Entesar Nayyef Farhan \\ en1962farhan@yahoo.com \\ General Directorate of Vocational Education -Baghd
}

\begin{abstract}
In this paper the FE simulation and experimental equipment and design of the system for deformation by single point incremental sheet metal forming are presented. The formability is executed at room temperature and needs the milling machine, the tool of hemispherical head and toroidal head applied to deform the sheet, whereas translates from the peripheral of the sheet to its focus that additionally driving the sheet down. The blank is distorted increment by increment into the required shape via hemispherical or toroidal nose instrument going along a circular way. In the present investigation, the deformation's analyses were down on the aluminum 7075 compound with thickness $(0.9 \mathrm{~mm})$ and various device nose are enormously impact on the contact region and its observed that the hemispherical apparatus gives the best outcome. Close to this investigation consequence of the impact of shaping instrument nose on the formability is displayed. The ANSYS results are comparison with results obtained experimentally and it's discovered the deviation about $8 \%$ and this is expected to the criteria of spring-back.
\end{abstract}

Key words: Plastic forming; Single point incremental forming; Strain distribution; ANSYS, finite element method, Aluminum alloy 7075 .

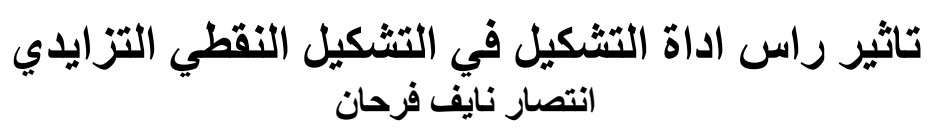

الخلاصة

في هذا البحث، يتم تقديم محاكاة باستخدام طريقة العناصر المحددة والاجر اءات التجريبية وتصميم نظام للتشوه من خلال

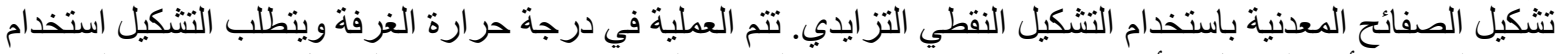

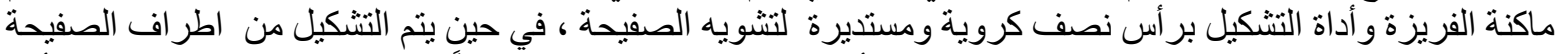

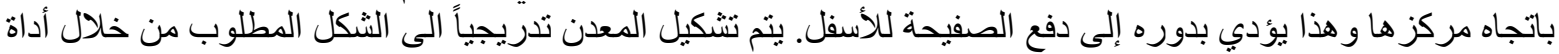

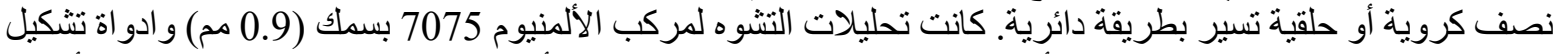
نقطي مختلفة الر اس حيث تبين ان له تأثير كبير على منطقة التلامس و لاحظ أن أن اداة ذات النصف النف الكروي يعطي أفضل

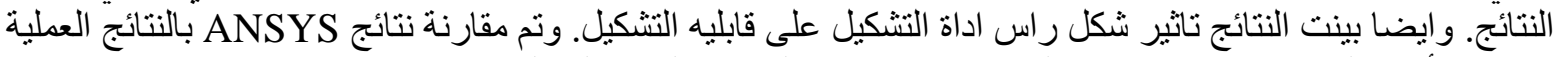
و اكتثف أن هنالك بعض الانحر اف حوالي 8 ٪ و هذا منوقع لمعايير العودة إلى الور اءك. 


\section{INTRODUCTION}

A lot of the industrial parts utilized the forming operation such as deep drawing and stamping to generate forming in the metals parts. These processes requested large initial investments and long die preparation times, with special dies for each parts. The increment forming by single-point (SPIF) is introduced, with the purpose of minimizing the manufacturing costs and product time. SPIF is the flexible metal of sheet forming techniques. The forming of increment procedure is begun from sheet forming and turning process. In this way, SPIF procedure has consolidated points of interest of stretch shaping procedures and metal turning process. Incremental forming is another procedure for disfiguring metals of sheet by the utilization of bit via bit gradual feed to a deform device. In the creation of sheets by customary shaping sheet methods, devoted apparatuses are needed. The committed apparatuses are unpredictable 3D structure and subsequently are costly. The structure for apparatus for confounded shapes is extremely troublesome and exorbitant. In the forming by increment system, just a disfiguring device is needed for distorting the sheet metals. Four essential components of a SPIF procedure as appeared in Figure(1) metal of sheet, a holder of blank, tool of forming as single-point, and milling machine. There is various application domain of SPIF, that many items is needed for the accuracy for an exhibition. Domain could be made via SPIF as the following: Automobile: board of internal door, external door board, board of hood, spread's motor, and telephones of cellular; Aerospace Industry: board of instrument, board's body, seat of spread's traveler, and so on. High items: Plate of denture, support of ankle, metal cap, and so on.; IC lead frame; care of health; latches of miniature; drives like hard disk; products of national security; Automobiles; and Sensors. Single-point gradual framing (SPIF) is a sheet metal shaping procedure that permits fabricating parts without advancement of complex devices in correlation with the process of stamping (Thibaud S et al., 2012). SPIF procedure depends firmly on the forming apparatus way which impacts extraordinarily the geometry of part and the distribution of sheet thickness (Azaouzi M. and Lebaal N., 2012). M. Skjoedt et al., 2009, concentrated for use SPIF of multistages used the target for creating cups shaped with walls vertically. System comprises for conical forming cup used a decrease point on primary step, trailed via three resulting steps which dynamically form the cone shaped to the required shape for cylinder. Y. Luo et al., 2010, built up another ISMF strategy dependent on increment sheet punching that is shaped with the last shape via a progression for little increment punches R. Aerens et al., 2010, introduced reasonable formula permitting to foresee the powers happening during the single point increment forming procedure. R. Malhotra et al., 2011, investigates capacities of DSIF as far as developing the geometrical precision when contrasted with SPIF via utilizing a novel way of tool methodology in which the sheet is privately crushed between the two instruments. C. Henrard et al., 2011, concentrated the precision of the techniques via finite element method in foreseeing the instrument power happening through the increment point singly forming (SPIF) procedure. R. Malhotra et al., 2012, created the model of crack using finite element techniques to anticipate event for damage in SPIF for two stage of shapes, cone and funnel. Analyses are executed for approve expectations in FEA as far as shaping powers, thinning and depths of fracture. C. Felipe Guzm et al., 2012, introduced twice SPIF, pyramid for the twice depth, that huge geometric deformation that looking at the proposed and final shapes are tested, that recognize if these divergences are because of new plastic strain whereas shaping the subsequent point pyramid by utilizing finite element techniques. Malwad and Nandedkar, 2014, exhibited analyses were directed to analyses the distortion component of alloy of aluminum. Close to this investigation consequence of the impact of angle of forming, size's 
step, apparatus measurement on formability and thickness distribution of wall are exhibited. Shakir Gatea et al., 2019, exhibited trials and FE investigations are led for assess the impact for the fundamental ISF procedures' parameters inclusive the progression down, rate of feed and apparatus distance across on the formability and crack for two sorts of pure Ti (class one and two). Pranav Gupta and Jacob Jeswiet, 2019, investigation components impacting the stepping of forming procedures for single point increment. It gets the depiction for systems utilized to reproduce non-straight conduct for metal's sheet shaping alongside a certain and express philosophy. Data for the determination for component kind inclusive the component of Reduced Enhanced Solid-Shell is introduced.

The survey illustrates that ISF technique is very much explored, however a few works not surely knew in increment forming as dispersion of strain on the sheet for the length of distortion, impact of tool nose in ISF.

\section{TOOL PATH}

The choice of the correct apparatus way depends on the geometry unpredictability, the sheet metal, sheet thickness, completion of the surface, and milling machine (A. Blaga, 2011). However, chose device ways may be acknowledged successfully just that standards of the metal forming are indicated. The standards joined whereas producing device ways on ISMF procedure are arranged. In request for shape generation, the fundamental device is moved in the position of $Z$ via predefined sum called as Z-increment appeared in Figure(2). In the event that these areas are not appropriately moved, the increment often deliver a nonstop line of tool on the formed part. This is urgent especially that the geometry to be formed comprises for the surfaces of three dimension geometry considerable number of surfaces is significant. In such cases, the line of increment ought to be occupied along edges or corners, with the goal which increment impact is disguised. Something else, circular tool way maintains a strategic distance from such an issue, due to the Z-increment for a total rounding is uniformly dispersed along which round and augmentation imprint line is missing. Hence, some average device connects with movements before starting a round is valuable to limit the incremental marks.

\section{EXPERIMENTAL PART}

The experimental arrangements alongside these components are appeared in Figure(3). the significant operational segments are a fundamental tool's forming process, holder's apparatus, a blank, and SPIF-installation. The arrangement stays standard of various scales of the parts may be delivered, in light of the fact that every one of these segments is planned and actualized by the thought of generation various parts with shapes and sizes.

\section{Tools of Forming}

In request to create different parts, two device's instruments with different nose are made. Hemispherical and Toroidal. In this study the forming parameters are (diameter of tool "D", size of increment size $\Delta z$, instrument shape $S$, speed of rotation $\omega$, the progression of addition descending $(\Delta z)$, it's the estimation of deformed metal with each revolution of forming tools. As to shape parameter, hemispherical and toroidal head apparatuses are utilized. The device of toroidal nose has major and minor radii at the tip, while the hemispherical head instrument has one radius. Table (1), outlined the forming instrument shapes that utilized.

The head shape of hemispherical was chosen because of its even nature from focus making the instrument way improvement simpler. Besides, the device head has progressively uniform contact region, Figure(4) illustrate distinctive size of shaping apparatus. Flat with round 
corner device additionally is structured and actualized in this study, Its will in general experience instrument way improvement or contact region issues.

\section{Apparatus for Clamping}

In this study, a device of clamping was planned, actualized and utilized to maintain the blank in vertical plate's table of milling's machine. Gathering viewing and crossing areas view are represented separately as Figure(5). This apparatus is made out of a few sections:

1. The Support, making some space under the part with the goal that it can free display, thus that the deformed surface is observed.

2. Plate's top, that principle backing for the part, utilized for focus the plate's support and give the framework an adequate amount of unbending nature;

3. The backing plate, that is expected to counteract the grant displacement of the part and to get rounding edges.

4. Plate's clamping, that rushed upon the top's plate so as to press the part edges among the top plate and backing plate, in this way keeping it from sliding.

5. Base's plate, that is associate with machine's table.

\section{Blank Material}

The essential spaces have been drawn with radius round $5 \mathrm{~mm}$ as showed in Figure(6) to decide the strain in conclusive item. Aluminum alloy 7075 with $0.9 \mathrm{~mm}$ thickness was picked due to its ease and has good properties like better thermal conductivity, high shear strength, resistance of abrasive, operative at high-temperature, non-combustibility, and the able to be formed and treated on ordinary devices. It has good properties of casting. The chemical composition of Al-Alloy 7075 illustrated in table 2. Utilizing Universal Testing Machine (UTM), the tensile test was examining. The samples utilized with standard of ASTM E8. The mechanical properties of AA7075 is:

Tensile strength $=112.39 \mathrm{MPa}$, yield stress $=101.26 \mathrm{MPa}$.

Elastic Modulus $(\mathrm{GPa})=70-80=71.7 \mathrm{GPa}$

Density $(\mathrm{g} / \mathrm{cc})=2.81$, Poisson's ratio $=0.33$, Hardness $($ HB500 $)=60$

\section{SINGLE POINT INCREMENTAL METAL FORMING SIMULATION}

In this examination, a wide useful of straight and nonlinear FEM investigation program, ANSYS15 is utilized to build up the model of finite element method (Nakasone Y. and Yoshimoto S, 2006), that is attempted for making a genuine forming procedure. APDLANSYS commands file is made to simulate the ISFP. An axisymmetric model of the 2D model with a progressively full model portrayal managed by a 3D model. For the shape and the boundary's condition (load) for the framework is approximated via an axisymmetric case, the three-dimensional model's computation was passed (Hani Aziz Ameen, 2010). ANSYS15.0 was utilized to simulate the ISPF procedure, where the "Newton-Raphson" with approach of implicit was utilized to solution the nonlinear case. In this methodology, the steps of the stroke on the device were characterized explicitly over a time's period. Inside each progression, a few arrangements "sub-steps or time steps" were implements to subject the incremental displacement, within each sub step, many iterations were used to get the solution in converge. Prior to every arrangement, the Newton-Raphson strategy assessed the out-ofbalance vector of load, that was the distinction between the restore powers (the loads indicated to the stresses of element) and the subjected loads. The program than played out a solution of linear arrangement, utilizing the out-of-balance vector of loads and examine for non-divergence. Whether the creation of converge was not fulfilled, the out-of-balance vector 
of loads was reexamined, therefore update the stiffness matrix, and another solve arrangement was gotten. This iteration strategy proceeded until the convergence is exists. Plane 182 structural solid element is used, which has 4-node and it was utilized for meshing the blank and tool. The frame was modeled as a rigid body. The development of the apparatus was characterized utilizing a pilot node.

Programmed contact method in ANSYS15.0 was utilized to demonstrate the connection between the blank and tooling (ANSYS 15.0, User guide, 2015). The model of SPIF was made. since the axisymmetric in the geometry of blank and the boundary conditions. Twodimensional axisymmetric part of the model required was be examined. The geometry of the SIF utilized in the ANSYS simulation is illustrated in Figure(7). Three hemispherical and toroidal tools radius are used $(\mathrm{R}=4,5$, and 6) $\mathrm{mm}$, with $200 \mathrm{~mm}$ diameter of the blank.

\section{ANSYS Setup}

Firstly, drawing the two-dimension axisymmetric model using APDL-ANSYS code and then used Automatic contact arrangement as illustrated in Figure (8). to joint between the parts, utilizing the contact of surface-to-surface and node-to-surface. Finally, the transient solution is used to solve the incremental nonlinear SPIF using the unsymmetrical Newton-Raphson option with 200 iterations at each sub-step till achieving the convergence.

\section{RESULTS AND DISCUSSION}

As per the outcomes got from the test it was discovered that under the equivalent forming conditions the hemispherical apparatus is more appropriate than the toroidal device since it had the option to form more depth than the toroidal without causing a crack as appeared in Figures(9 and 10). So as to examine the distribution of strain in the products, the pattern of grid was set up on the surface in bottom side of sheet as appeared in figure(6). The cone have top's radius $\mathrm{R}=20 \mathrm{~mm}$ and bottom's radius $=5 \mathrm{~mm}$ is effectively delivered via SPIF with hemispherical device nose. Figures( 9 and 10) showed the deformed sheets. Figures (11 and 12), obviously seen the distributions of strains and stresses using hemispherical profile and Figures(13 and 14) illustrated the strains and stresses using toroidal profile. From these figures, it can be observed that the deformed sheet are greatly depends on the forming tool profile. The impact of on are enormously relies upon the contact region for a similar geometry of the forming instrument, therefore the diameter's tool expanded the contact zone increment and the stresses and strains are decreased as showed in Figures (15 and 16).

\section{CONCLUSIONS}

1. The SPIF is an adaptable, high proficiency, brief time for structure and cheap strategy for generation sheet items yet a procedure is relative moderate and just reasonable to little generation batch and fast model creation.

2. Experimental and ANSYS results are compared and it's discovered that there is a deviation about $8 \%$ and this is expected to creation of spring-back.

3. Aluminum alloy has been utilized in this study having $0.9 \mathrm{~mm}$ thickness with various instrument nose are incredibly impact on the contact region, and its discovered that the hemispherical device gives the best outcome.

4. It's observed that the ANSYS's results illustrated that the essential impact factor for the contact zone among the apparatus and the sheet, like the radius of a tool increasing the contact region are increasing and as the increasing the depth of forming, the region of the contact increased too of both tool's radius and depth of formed where this play a critical move on stress and strain conduct. 


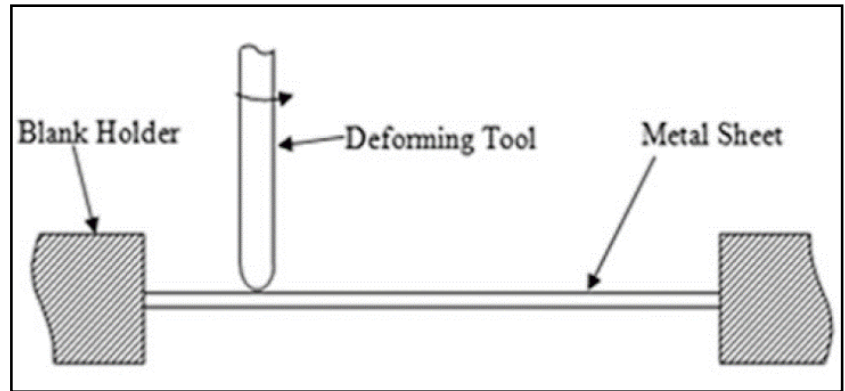

Fig.(1): Elements for incremental sheet forming process
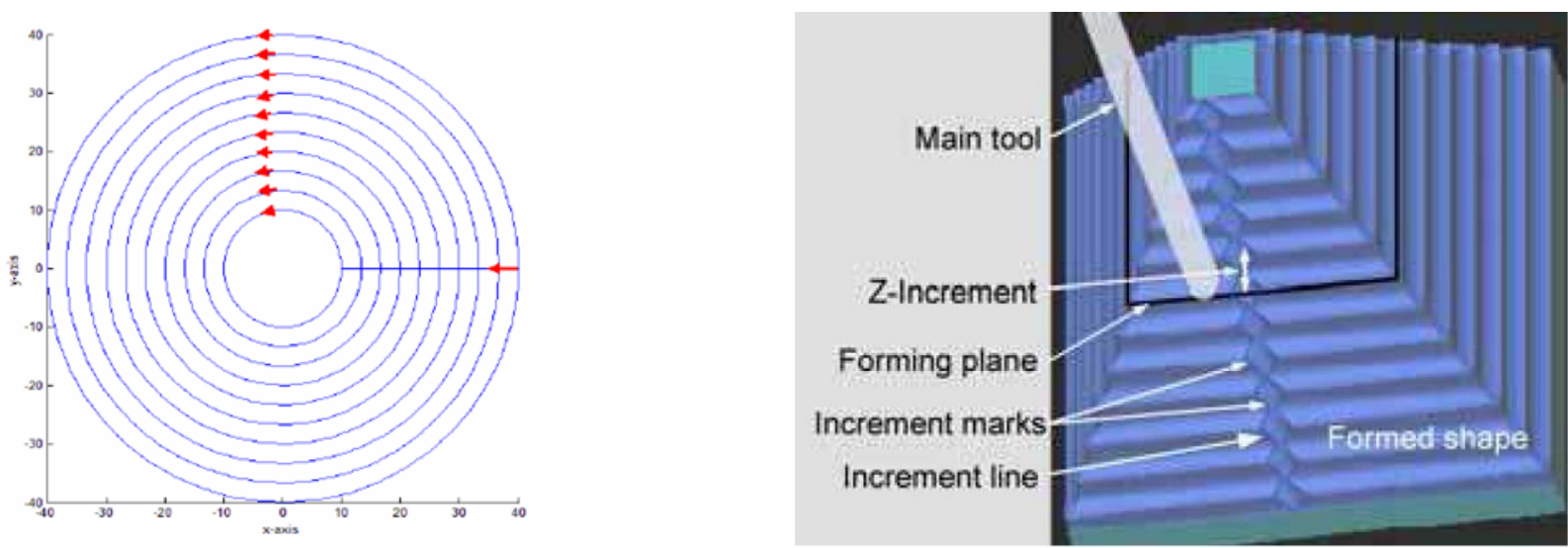

Fig.(2): Assignment of Tool Path

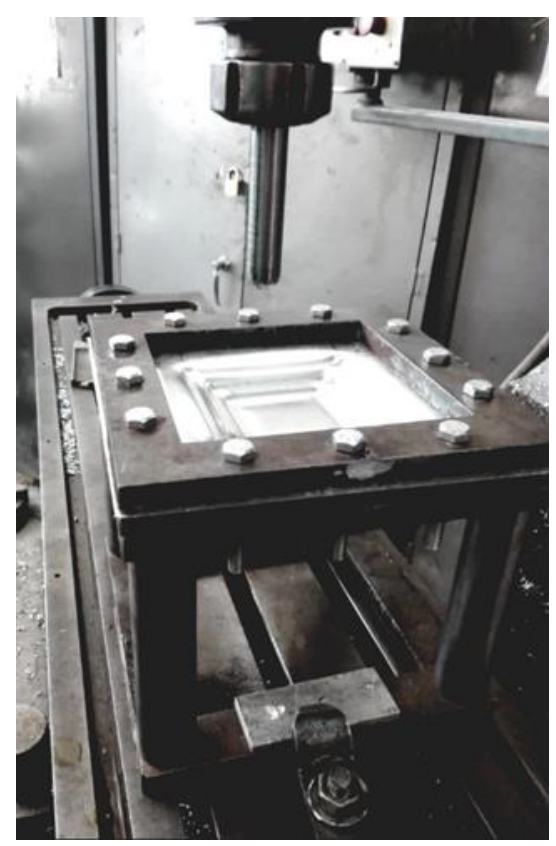

Fig.(3): Experimental arrangements 

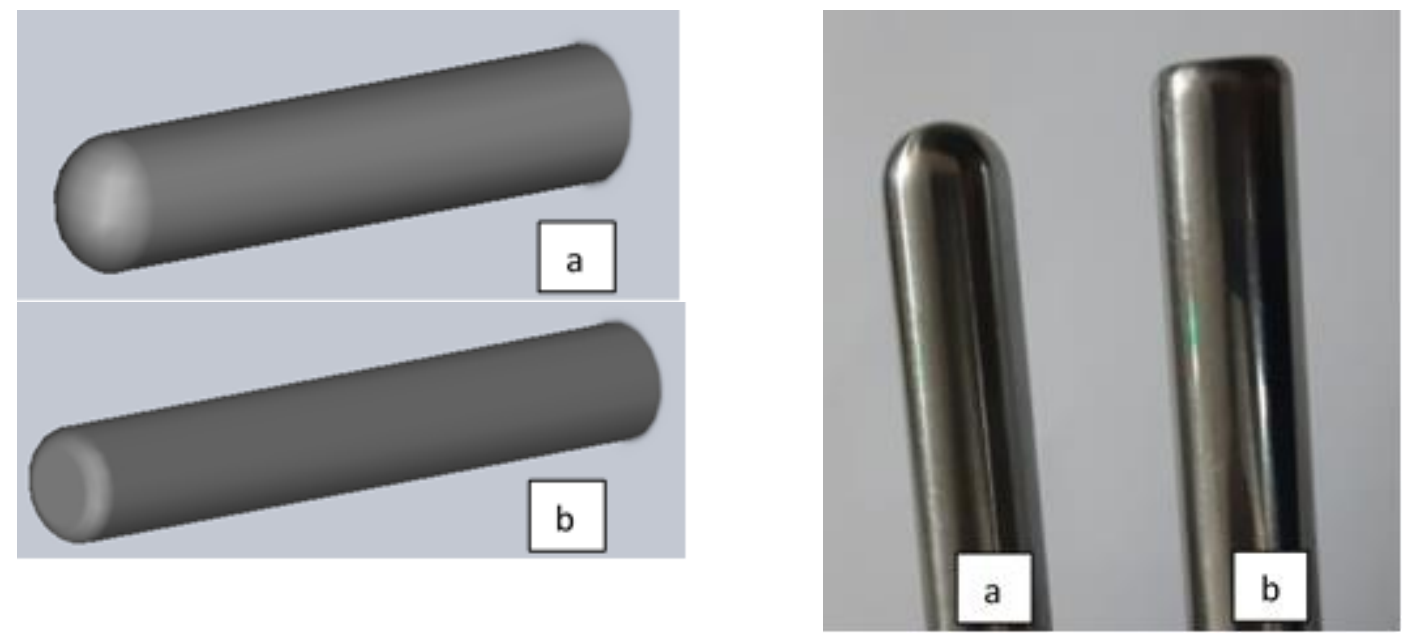

Fig.(4): Tool of Forming: a- Hemispherical b- Toroidal
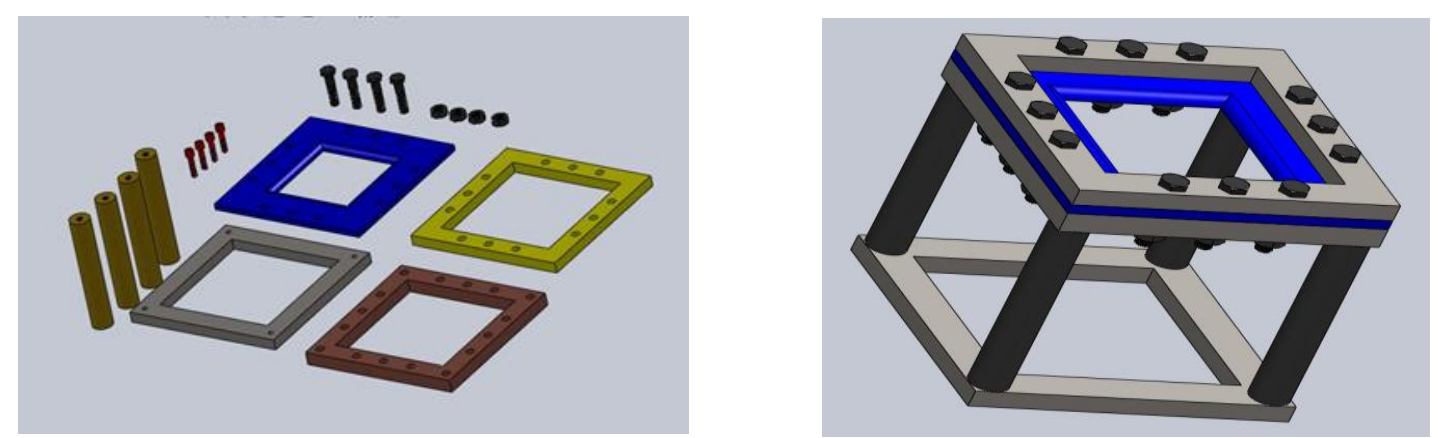

Fig.(5): Structure of SPIF

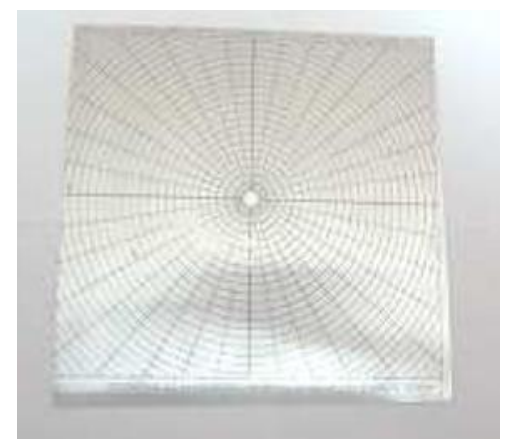

Fig.(6): Grid for strain measurement 


\section{THE FORMABILITY OF SINGLE POINT}

\section{INCREMENTAL SHEET FORMING}
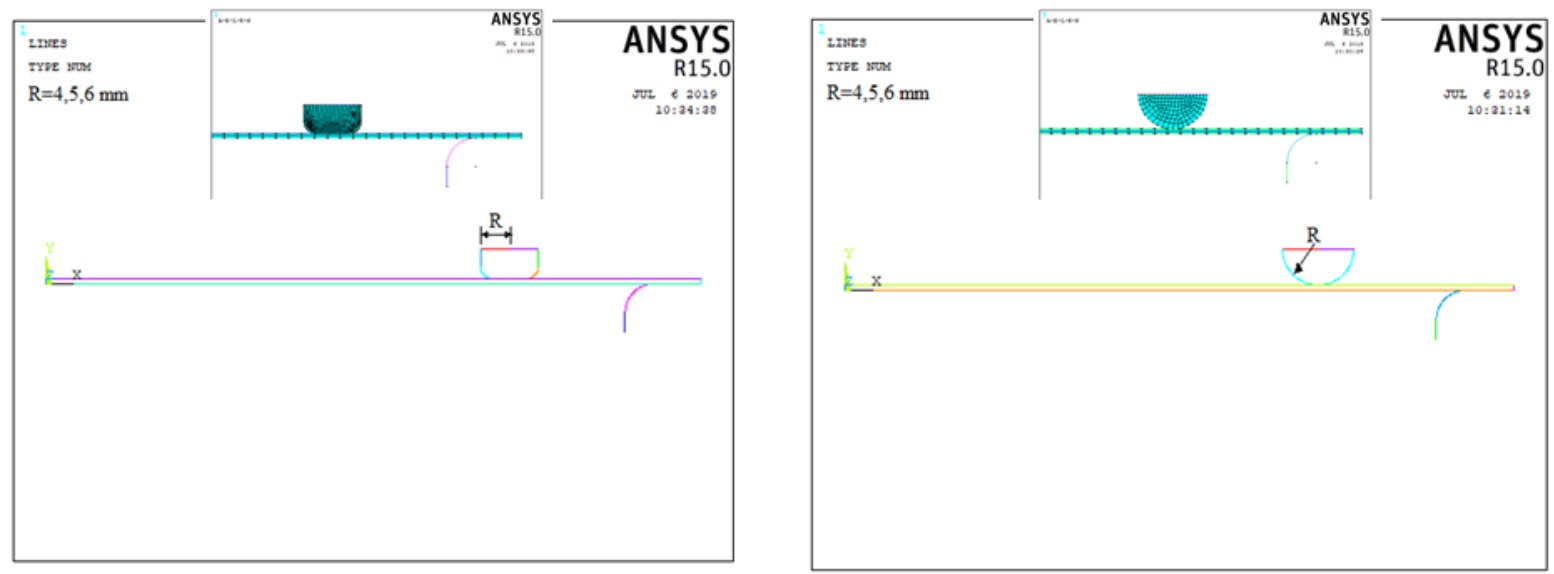

Fig.(7): SPIF ANSYS model

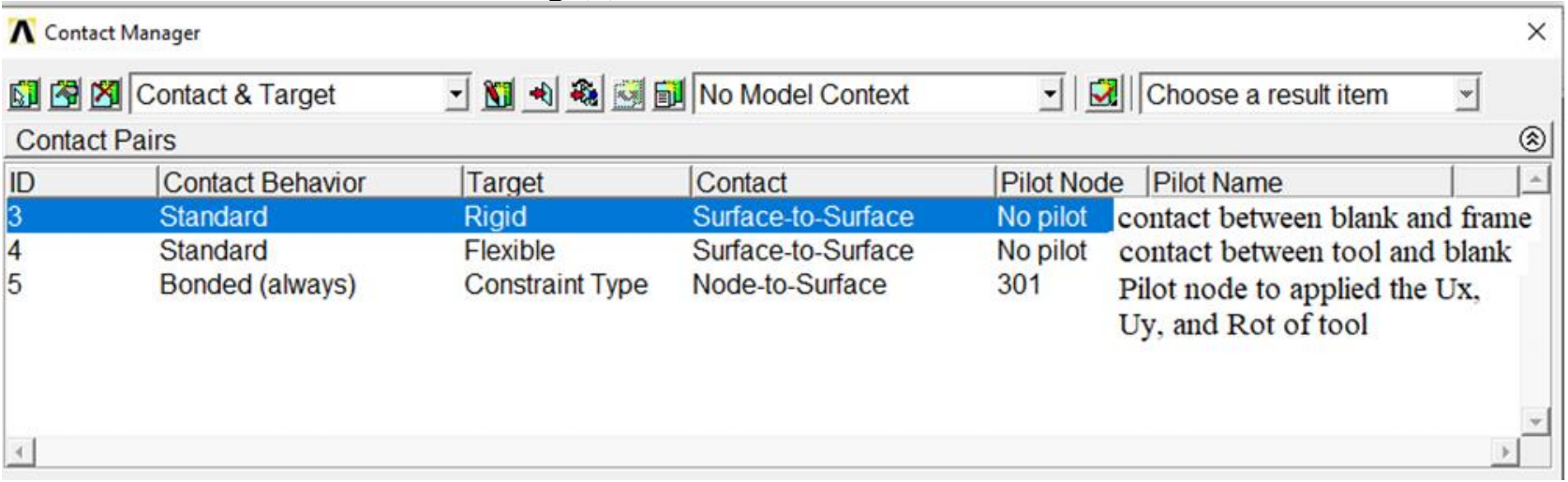

Fig.(8): Contact manager arrangement for SIFP
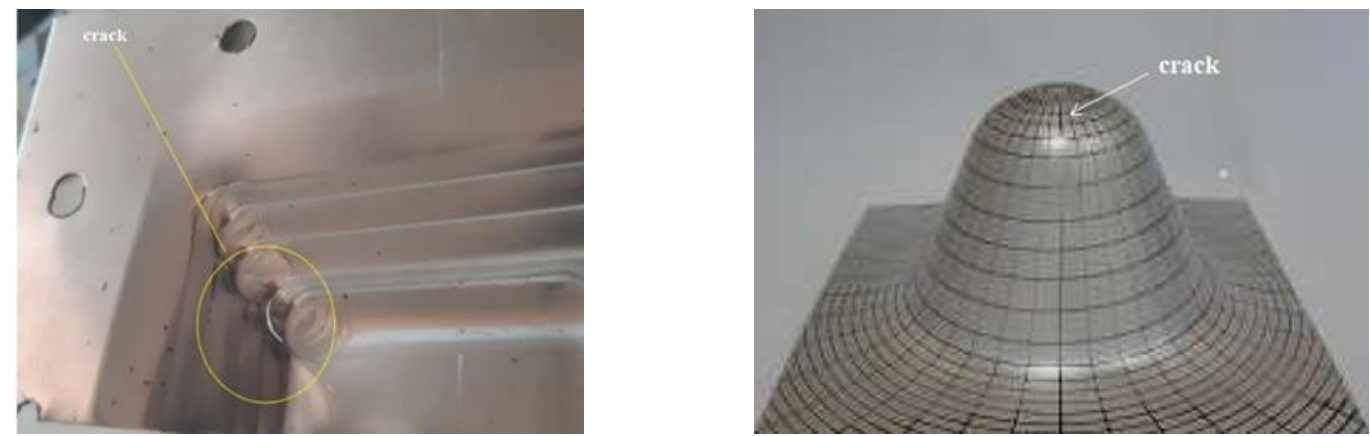

Fig.(9): crack in sheet (toroidal tool)
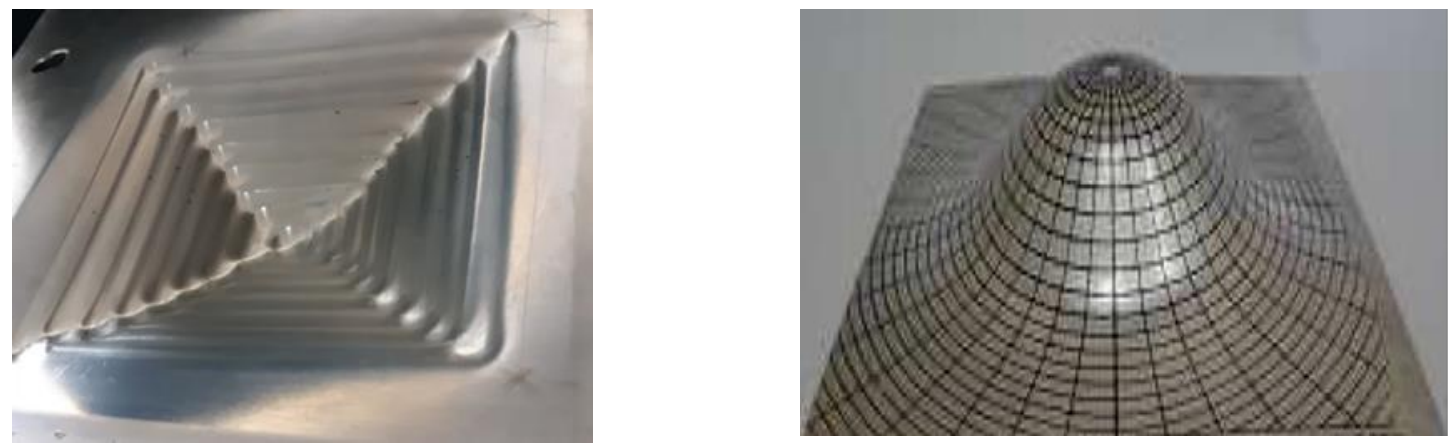

Fig. (10): no crack (hemispherical tool) 


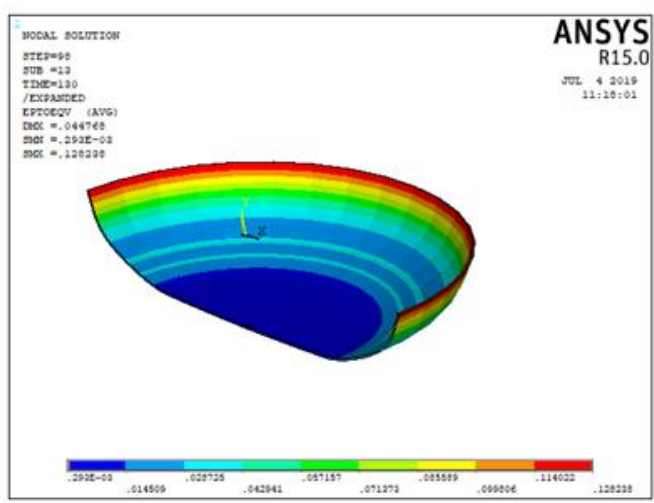

(a) $\mathrm{R}=4 \mathrm{~mm}$

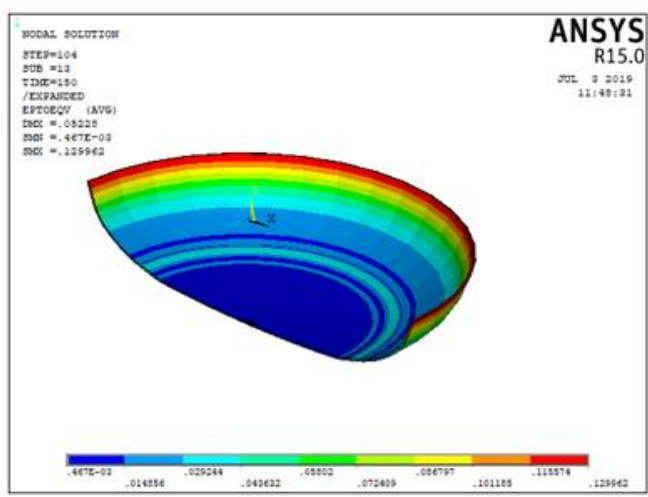

(b) $\mathrm{R}=5 \mathrm{~mm}$

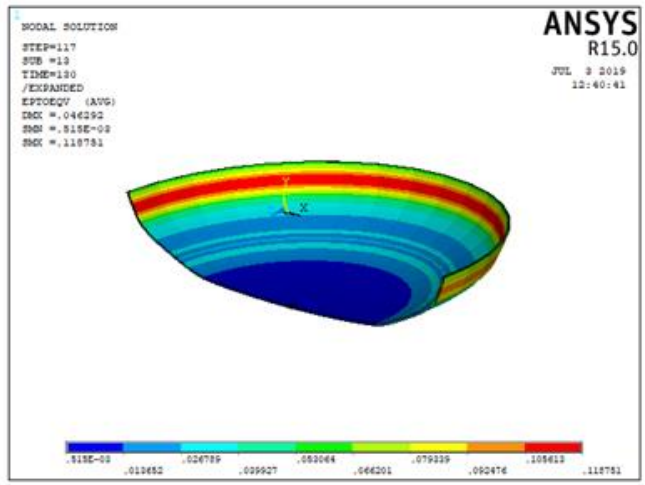

(c) $\mathrm{R}=6 \mathrm{~mm}$

Fig.(11): Strain distributions using hemispherical profile

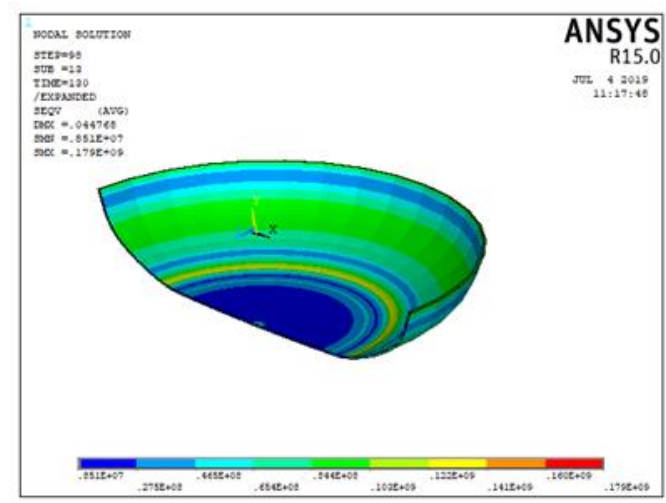

(a) $\mathrm{R}=4 \mathrm{~mm}$

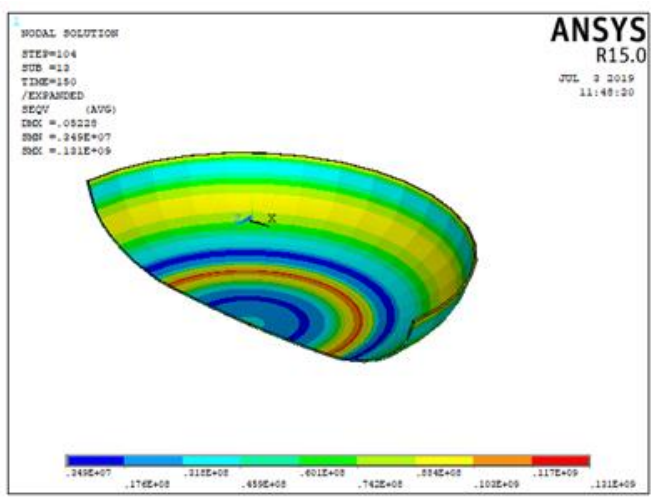

(b) $\mathrm{R}=5 \mathrm{~mm}$

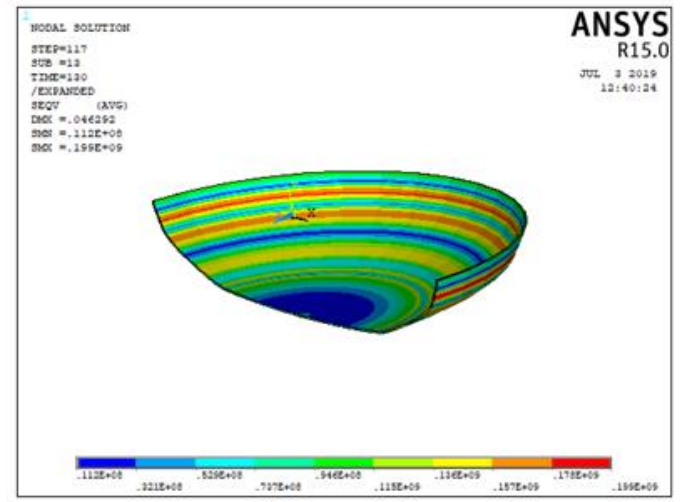

(c) $\mathrm{R}=6 \mathrm{~mm}$

Fig.(12): Stress distributions using hemispherical profile 


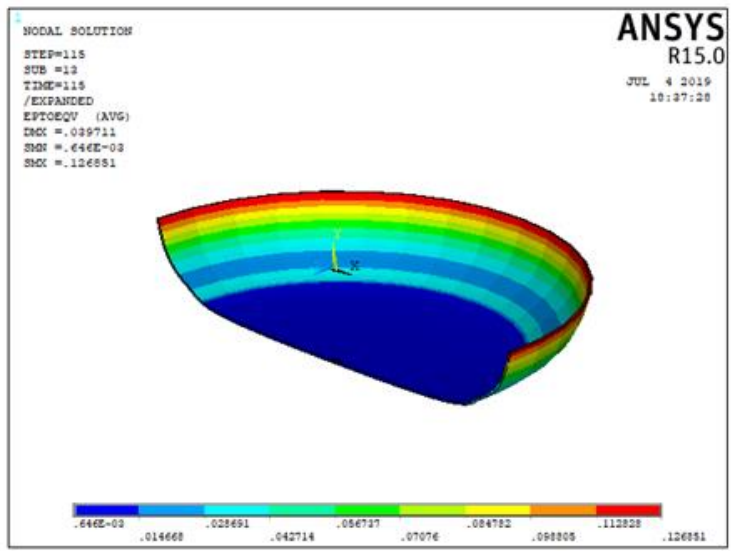

$\mathrm{S}=2$

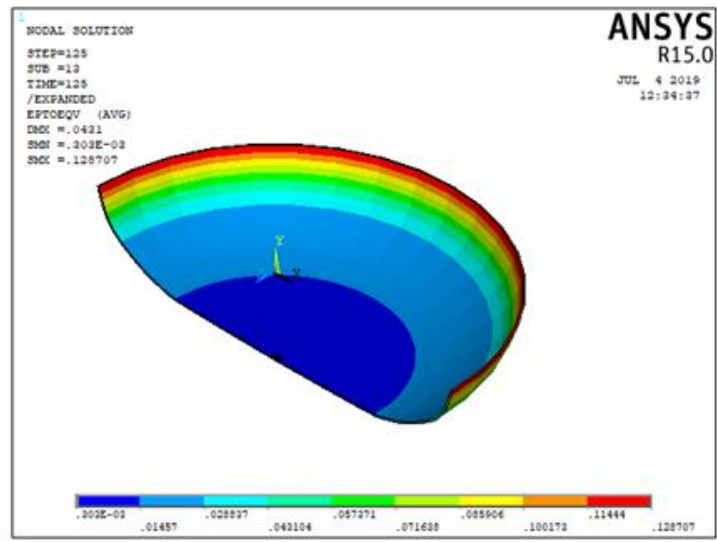

$\mathrm{S}=2.5$

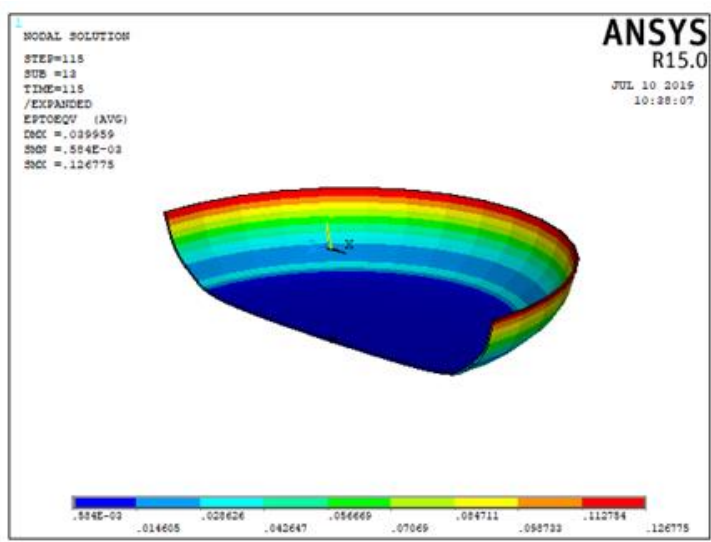

Fig.(13): Strain distributions using Toroidal profile $(\mathrm{S}=\mathrm{R} / \mathrm{r})$

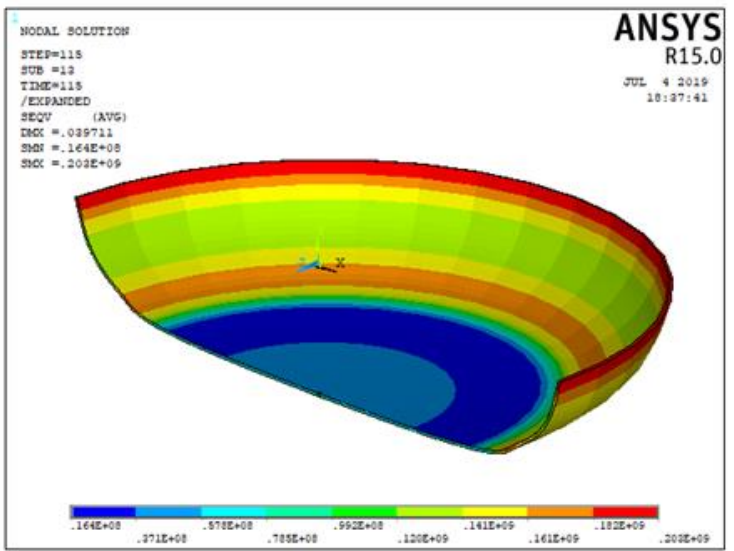

$\mathrm{S}=2$

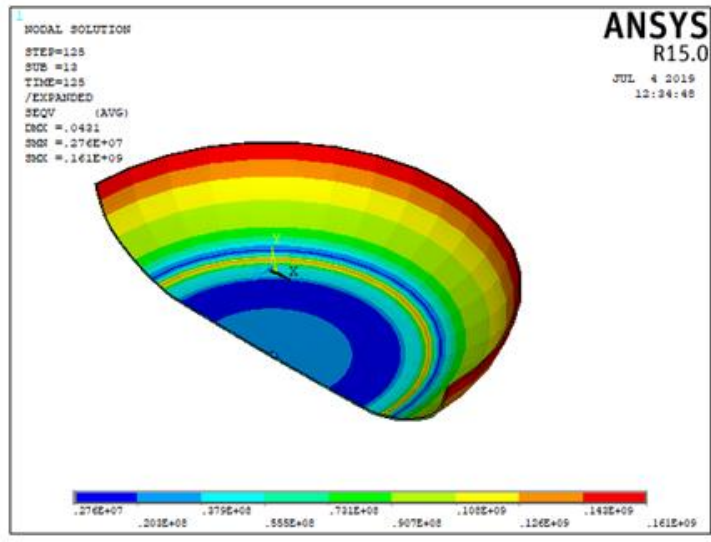

$\mathrm{S}=2.5$

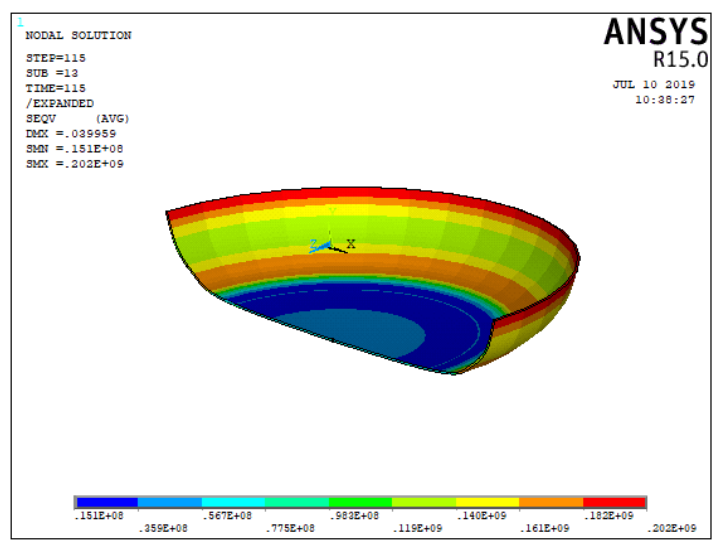

Fig.(14): Stress distributions using Toroidal profile $(\mathrm{S}=\mathrm{R} / \mathrm{r})$ 


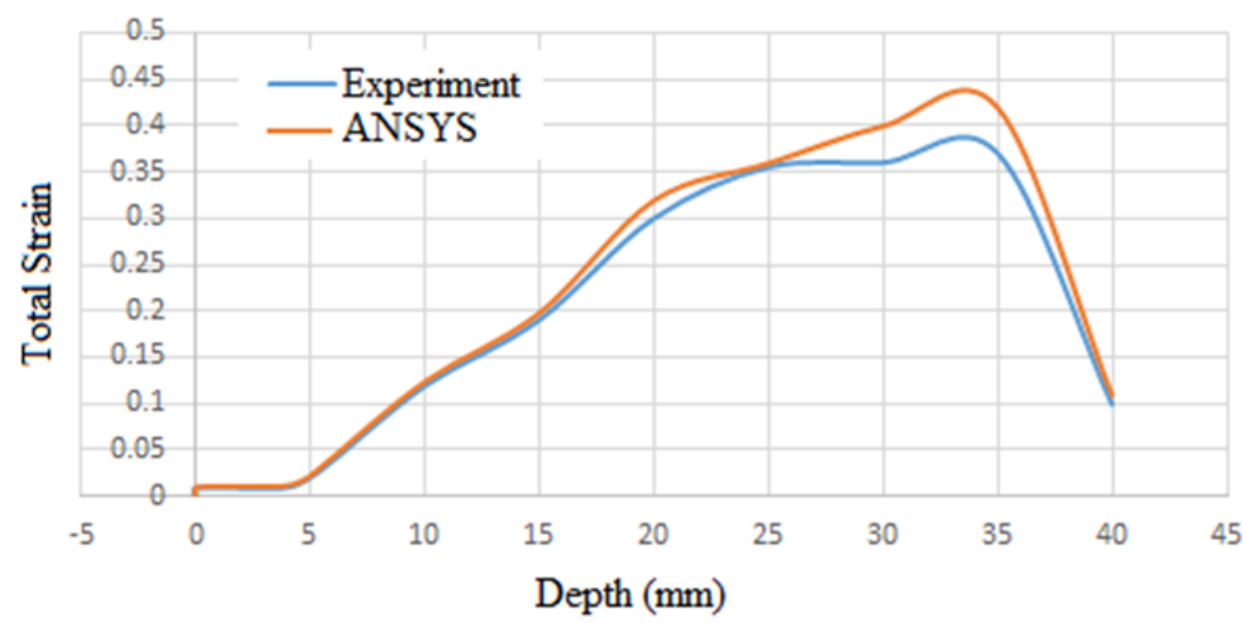

(a) $\mathrm{R}=4 \mathrm{~mm}$

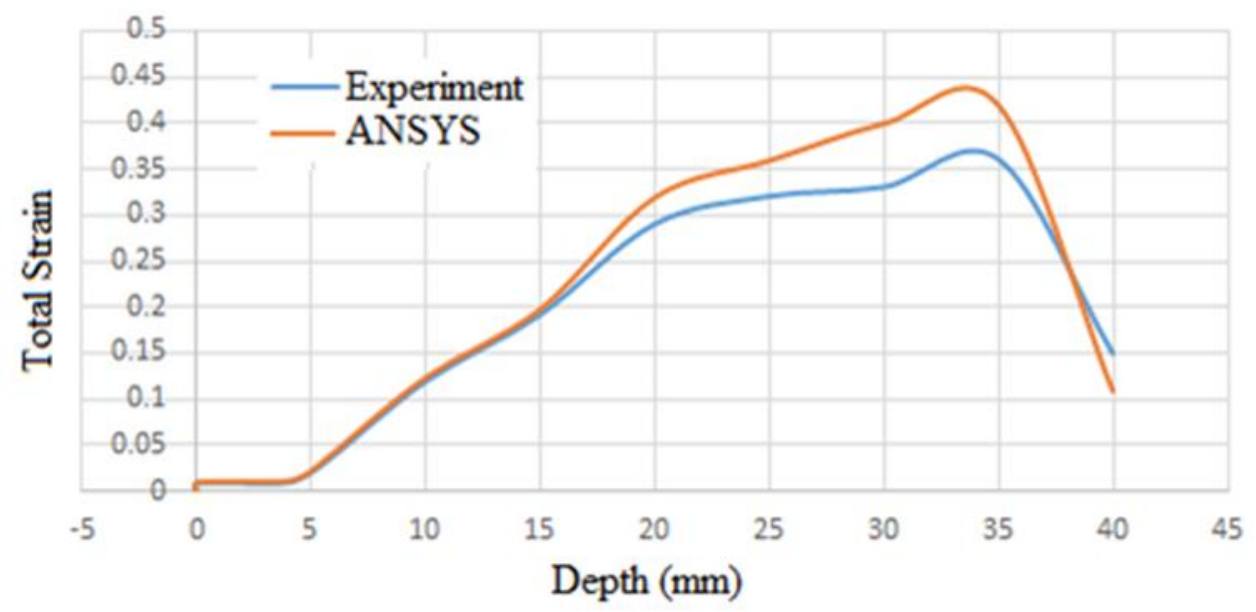

(b) $\mathrm{R}=5 \mathrm{~mm}$

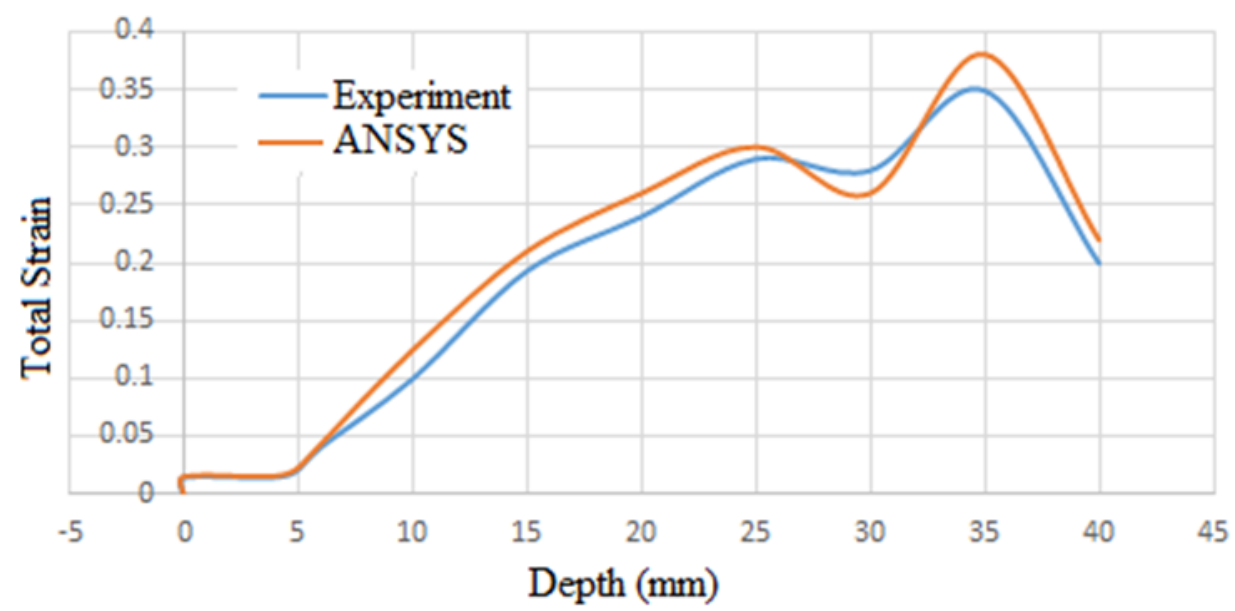

(c) $\mathrm{R}=6 \mathrm{~mm}$

Fig. (15): Strain distribution experimentally and ANSYS for hemispherical nose with different radius 


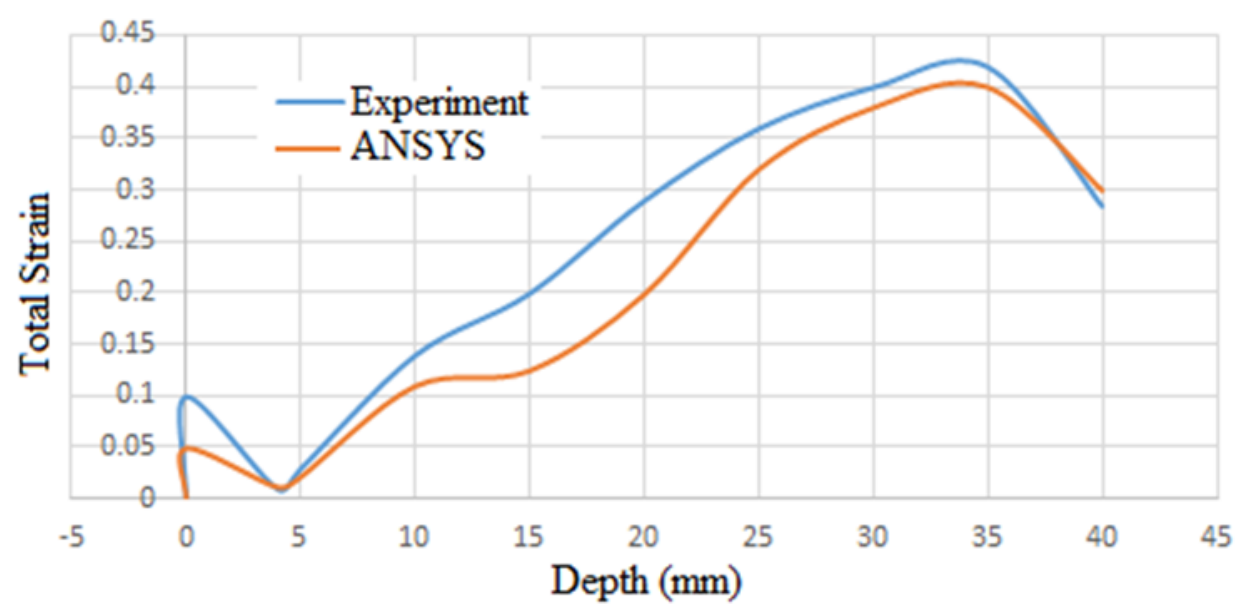

(a) $\mathrm{S}=2$

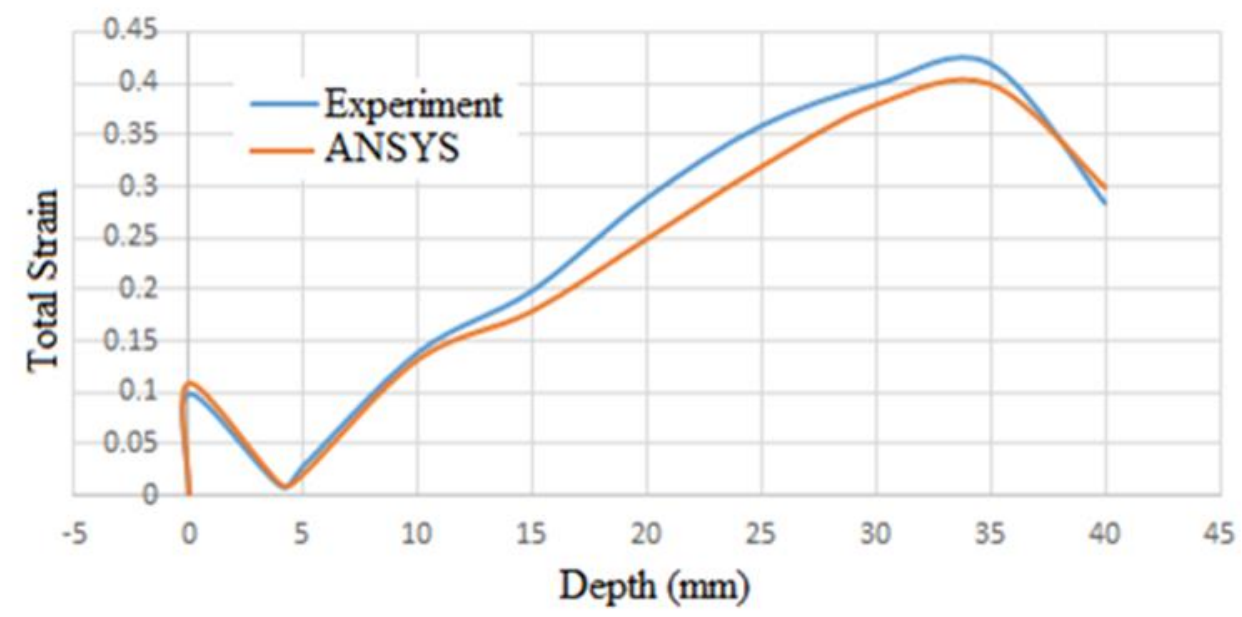

(b) $\mathrm{S}=2.5$

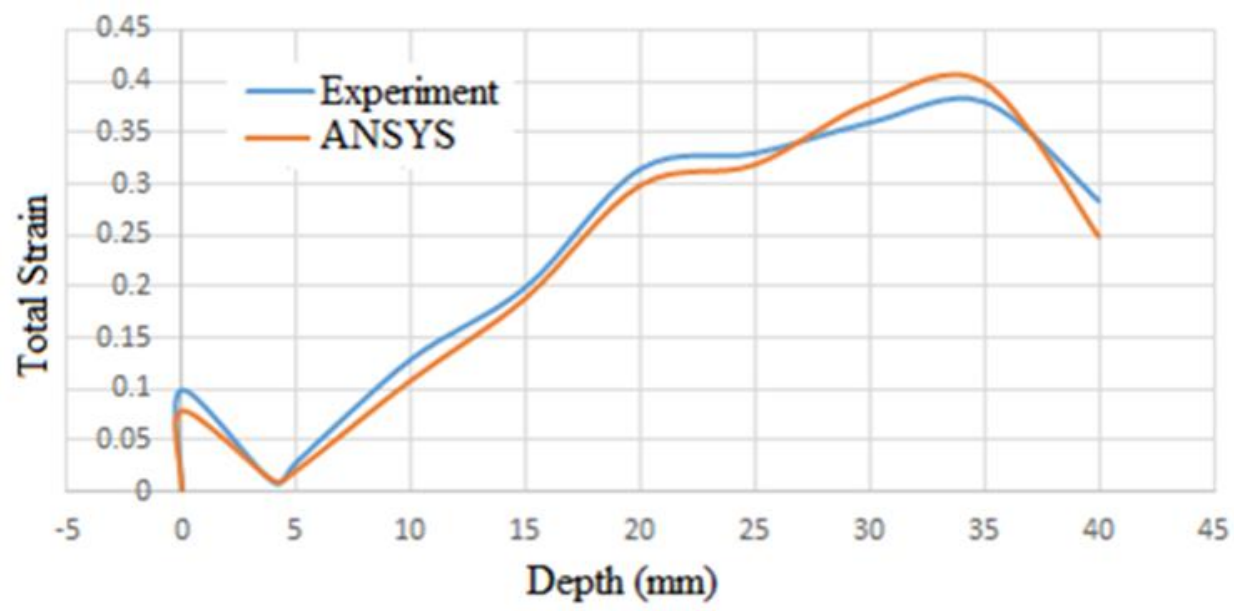

(c) $\mathrm{S}=3$

Fig.(16): Strain distribution experimentally and ANSYS for Toroidal nose with different radius 
Table (1): Shapes of forming tools

\begin{tabular}{|c|c|c|c|}
\hline Type of Tool & $\mathrm{R}[\mathrm{mm}]$ & $\mathrm{R}[\mathrm{mm}]$ & $\mathrm{S}=\mathrm{R} / \mathrm{r}$ \\
\hline \multirow{3}{*}{ Toroidal } & 4 & 2 & 2 \\
\cline { 2 - 4 } & 5 & 2 & 2.5 \\
\cline { 2 - 4 } & 6 & 2 & 3 \\
\hline \multirow{3}{*}{ Hemispherical } & 4 & 4 & 1 \\
\cline { 2 - 4 } & 5 & 5 & 1 \\
\cline { 2 - 4 } & 6 & 6 & 1 \\
\hline
\end{tabular}

Table(2): Chemical Composition of AA7075

\begin{tabular}{|l|l|l|l|l|l|l|l|l|l|}
\hline Elements & $\mathrm{Si}$ & $\mathrm{Fe}$ & $\mathrm{Cu}$ & $\mathrm{Mn}$ & $\mathrm{Mg}$ & $\mathrm{Cr}$ & $\mathrm{Zn}$ & $\mathrm{Ti}$ & $\mathrm{Al}$ \\
\hline Nominal (Wt. \%) & $\begin{array}{c}0.4 \\
\text { (Max.) }\end{array}$ & $\begin{array}{c}0.5 \\
(\text { Max.) }\end{array}$ & $\begin{array}{l}(1.2- \\
2)\end{array}$ & $\begin{array}{c}0.3 \\
(\text { Max.) }\end{array}$ & $\begin{array}{l}(2.1- \\
2.9)\end{array}$ & $\begin{array}{c}(0.1- \\
0.28)\end{array}$ & $\begin{array}{l}(5.1- \\
6.1)\end{array}$ & $\begin{array}{l}0.2 \\
\text { (Max.) }\end{array}$ & Bal \\
\hline Measured(Wt. \%) & 0.00077 & 0.3 & 1.26 & 0.109 & 2.33 & 1.19 & 5.72 & 0.0005 & Bal \\
\hline
\end{tabular}

\section{REFERENCES}

Thibaud S., Hmida RB., Richard F., Malécot P., (2012) "A fully parametric toolbox for the simulation of single point incremental sheet forming process: numerical feasibility and experimental validation”. Simul Model, Pract Theor, 29:32-43 .

Azaouzi M., Lebaal N., (2012), “Tool path optimization for single point incremental sheet forming

using response surface method". Simul Model, Pract Theor, 24:49-58.

M. Skjoedt, M. B. Silva, P. A. F. Martins and N Bay, "Strategies and limits in multi-stage single-point incremental forming", The Journal of Strain Analysis for Engineering Design, Vol. 45, 2009.

Y. Luo \& K. He \& R. Du, "A new sheet metal forming system based on the incremental punching, part 1: modeling and simulation" Springer-Verlag London Limited, Int J Adv Manuf Technol, Vol. 51, 2010.

R. Aerens, P. Eyckens, A. Van Bael and J. R. Duflou," Force prediction for single point incremental forming deduced from experimental and FEM observations", Springer-Verlag London Limited, Int J Adv Manuf Technol, Vol. 46, 2010.

R. Malhotra, J. Cao, F. Ren, V. Kiridena and Z. Cedric Xia," Improvement of Geometric Accuracy in Incremental Forming by Using a Squeezing Toolpath Strategy With Two Forming Tools", ASME, Journal of Manufacturing Science and Engineering, Vol. 133 /061019-1, 2011.

C. Henrard, C. Bouffioux, P. Eyckens, H. Sol, J. R. Duflou, P. Van Houtte, A. Van Bael, L. Duchêne and A. M. Habraken, "Forming forces in single point incremental forming: prediction by finite element simulations, validation and sensitivity", Springer-Verlag London Limited, Comput Mech, Vol. 47, 2011. 
R. Malhotra, L. Xue, T. Belytschko and J. Cao, "Mechanics of fracture in single point incremental forming", Elsevier Ltd, Journal of Materials Processing Technology, Vol. 212, 2012.

C. Felipe Guzm, J. Gu , J. Duflou , H. Vanhove , P. Flores and A. Marie Habraken, "Study of the geometrical inaccuracy on a SPIF two-slope pyramid by finite element simulations", Elsevier Ltd, International Journal of Solids and Structures, Vol. 49, 2012.

D. S. Malwad , V. M. Nandedkar, "Deformation Mechanism Analysis of Single Point Incremental Sheet Metal Forming”, Procedia Materials Science 6 ( 2014 ) 1505 - 1510.

Shakir Gatea , Bin Lu, Jun Chen , Hengan Ou , Graham McCartney, "Investigation of the effect of forming parameters in incremental sheet forming using a micromechanics based damage model", International Journal of Material Forming, , Volume 12, Issue 4, pp 553-574, July 2019

Pranav Gupta and Jacob Jeswiet "Parameters for the FEA simulations of single point incremental forming", Production \& Manufacturing Research, VOL. 7, NO. 1, 161-177, 2019.

A. Blaga, "Contributions to the incremental forming of thin metal sheets", PhD thesis, University of Sibiu, 2011.

Nakasone Y. and Yoshimoto S.,"Engineering Analysis with ANSYS Software", Department of Mechanical Engineering, Tokyo University of Science, 2006.

Hani Aziz Ameen "Study the stresses in deep drawing process using conical die", Journal of Kerbala University,Vol.8, No.1,Sientific,2010. (in Arabic) .

ANSYS 15.0, User guide, 2015. 